\title{
Políticas públicas y derechos políticos: Del voto femenino a las cuotas de género como respuestas a los problemas de representación política de las mujeres en la Argentina
}

Public Policies and Political Rights: From Women's Suffrage to Gender Quotas as Answers to Problems of Political Representation of Women in Argentina

Hernán Pablo Toppi

Licenciado en Ciencia Política por la Universidad de Buenos Aires, Magister en Políticas Públicas por la Universidad Torcuato Di Tella y Doctor en Ciencias Sociales por la Universidad de Buenos Aires. Docente e investigador en la Universidad de Buenos Aires y en la Universidad del Salvador. htoppi@sociales.uba.an
Fecha de recepción:

17.6.15

Fecha de aceptación:

5.1.16

\section{Resumen}

La incorporación de la mujer a la vida política argentina ha involucrado dos momentos cruciales. El primero vinculado al voto femenino y el segundo a las cuotas de género. Este trabajo analiza ambos procesos a partir del modelo secuencial de políticas públicas. Por un lado, sostendremos que dichos casos cumplen con las diferentes fases propuestas por el modelo. Por otro, propondremos que existe una conexión directa entre los casos mencionados, pues la aparición de un problema inesperado con la introducción del voto femenino llevará a las cuotas de género. Esto nos demostrará que el proceso de política pública no solo es dinámico sino también circular.

Palabras clave: Derechos políticos - Voto femenino - Cuotas de Género - Política Pública - Argentina.

\section{Abstract}

The incorporation of women to Argentina's political life involved two crucial moments. The first one is linked to women's suffrage and the second one to gender quotas. This paper analyzes both processes through the sequential model of public policies. On one hand, we will asses 
that those cases fulfill the different phases proposed by the model. On the other hand, we will propose that there is a direct connection between them, because of the emergence of an unexpected issue: the introduction of women's suffrage will lead to the gender quotas. This will show us that the process of public policy is not only dynamic but circular too.

Key Words:Political Rights - Women's Suffrage Gender Quotas - Public Policy - Argentina

\footnotetext{
"Aquellos revolucionarios constructores de democracias, enamorados de la justicia, que afirmaban con énfasis $y$ solemnidad, en documentos inmortales, que el derecho es inherente a toda existencia humana, cometieron el más absurdo de los errores negando a la mujer los derechos ciudadanos"

(Alicia Moreau de Justo, "La mujer en la Democracia”)
}

\section{Introducción}

Establecer las reglas de juego respecto a quiénes pueden acceder a los cargos representativos, es un aspecto no solo político sino también público, pues involucra a la sociedad desde el momento en que los individuos, en tanto ciudadanos, tienen el derecho a participar en todo proceso electoral (sea como votante y/o candidato). En línea con esto, el carácter universal de los derechos políticos ha devenido una condición básica para la democracia contemporánea. El cumplimiento de este requisito implica que hombres y mujeres deben disfrutar de las mismas posibilidades para votar en las elecciones y también, para aspirar a ocupar cargos públicos.

Acercarse en la Argentina a dicha igualdad ha sido parte de un proceso que recorrió dos momentos, vinculados al reconocimiento institucional de diversas problemáticas. Mientras que a mediados del siglo veinte la universalidad era restringida, al involucrar únicamente a los hombres, luego del regreso a la democracia en los años ochenta la problemática consistió en que a pesar de que hombres y mujeres ya tenían los mismos derechos políticos, los primeros contaban con mejores posibilidades para acceder a cargos representativos. Estas etapas decantaron respectivamente en la introducción del voto femenino y las cuotas de género. 
Eugenio Lahera Parada (2002) sostiene que la política pública corresponde a soluciones específicas concernientes a cómo manejar los asuntos públicos. A partir de esta idea sostenemos la importancia del análisis como política pública del proceso que involucra a ambos momentos. Esto es así, en tanto su estudio nos permite ilustrar tres cuestiones: 1) Al ser miembros de una comunidad, lleva a que el modo en que los representantes son elegidos se convierta en un asunto público; 2) los casos a estudiar recorren las etapas de un proceso de política pública: problema, agenda, discusión, decisión, implementación, evaluación; 3) podemos identificar diversas trayectorias sobre cómo la problemática es atendida y resuelta, vinculada cada una con la fuente desde la que es presentada:mientras que el proceso del voto femenino se inició en la agenda gubernamental, el vinculado a las cuotas de género lo hizo en la sistémica.

Este trabajo se organiza de la siguiente manera: primero, analizaremos en términos teóricos el proceso de política pública, ilustrando las diferencias entre las trayectorias recién mencionadas. A continuación, examinaremos el recorrido hacia la instauración del voto femenino. En tercer término, haremos lo propio con las cuotas de género. Finalmente, propondremos las conclusiones.

\section{La política pública: Un proceso dinámico con más de una trayectoria posible}

Un proceso de política pública es dinámico (Tamayo Sáez 1997). Es por esta razón que consideramos de utilidad el "modelo secuencial de políticas públicas". De acuerdo a James Anderson (1997), esta alternativa de análisis evita centrarse aisladamente en las preferencias de los actores (teoría de la elección racional), en las reacciones del sistema político a las demandas (teoría sistémica) o en las instituciones que determinan el canal por medio del cual se elaboran las políticas (teoría institucional), sino que presenta un proceso donde dichos factores entran en juego de manera conjunta. Esto resulta de estudiar el desarrollo de una política pública en etapas, las cuales las resumimos brevemente a continuación:

a) Identificación del problema: El inicio de un proceso de política pública, surge del reconocimiento de un problema que afecta al conjunto o parte de la comunidad y que, por ende, requiere de una solución (Parsons 1995; Tamayo Sáez 1997; Lahera Parada 2002).

b) Ingreso del problema en la agenda: El planteamiento de un problema no significa su traducción inmediata en una política pública. El proceso hacia esta última, debe recorrer aún otras etapas, siendo una de ellas la vinculada con la introducción del primero en la agenda. Sobre este tema volveremos más adelante.

c) Debate sobre alternativas: Al problema existente se le debe buscar una solución. Para esto, se establecen las metas que implicarían llegar a la resolución y cuáles son los posibles caminos (alternativas) para alcanzarlas (Tamayo Sáez 2002). 
d) Decisión por una de las alternativas: La decisión de adoptar una de las alternativas, debería desembocar en una solución técnica y políticamente viable al problema existente (Meny y Thoening 1992, Tamayo Sáez; 1997).

e) Implementación de la decisión adoptada: Tomada la decisión, llega el momento de su implementación. Como es un cambio en las reglas de juego, los actores involucrados deben estar al tanto de las novedades que se generan con dicha introducción en pos de velar por su correcta implementación (Pressman y Wildavsky; 1984).

f) Evaluación de los resultados: Si los actores tomasen decisiones en marcos de información completa (escenarios donde se sabe con certeza las consecuencias de las decisiones), la evaluación no sería necesaria, ya que se estaría en condiciones de conocer con anticipación los resultados. Sin embargo, la realidad suele presentar coyunturas de información incompleta (donde las inferencias previas respecto a sus resultados, tienen un menor nivel de seguridad), con la consiguiente presencia, en términos de la evaluación, de tres potenciales escenarios. Por un lado, el cumplimento de los resultados esperados. Por otro, la no concreción de los resultados predichos inicialmente. Finalmente, la posibilidad donde, independientemente de los resultados, aparezcan situaciones imprevistas en el diseño de la política pública inicial y que puedan generar nuevas problemáticas que requieran atención (Tamayo Sáez; 1997, Ostrom; 2010).

g) Terminación (en caso de ser necesaria): Finalmente tenemos la terminación, la cual puede devenir de tres escenarios posibles: primero, cuando el problema ha sido solucionado; segundo, cuando la política pública no ha logrado cumplir las expectativas; tercero, debido al cumplimiento de un ciclo. Sin embargo, la terminación es una etapa optativa ya que no necesariamente una política pública va a finalizar. Esta puede continuar si se considera importante su vigencia para el resguardo de los resultados alcanzados. Los casos a estudiar, ingresan en esta última opción.

\section{Dos trayectorias para el ingreso del problema en la agenda gubernamental}

En esta sección queremos volver a la etapa de la introducción de la problemática en la agenda, pues los dos casos que analizaremos en este trabajo (voto femenino y cuotas de género) responden a las diferentes trayectorias a partir de las cuales se puede activar el proceso de políticas públicas.

El gobierno en cuanto ámbito de promoción de políticas públicas (Lahera Parada; 2002), tiene acceso directo a la "agenda gubernamental", la cual responde a los problemas que en función de la visión del mundo de los gobernantes, deben resolverse. Ahora bien, no sólo el gobierno puede aspirar a la presentación de problemáticas para ser encaradas institucionalmente. También lo pueden hacer otros sectores políticos o civiles que expresan problemá- 
ticas diferentes a las existentes en la agenda gubernamental. Debido a esto, Roger Cobb y Charles Elder (1984) introdujeron la "agenda sistémica", la cual contempla a todas las problemáticas existentes en una comunidad (de ahí su mayor abstracción) y con las que puede aspirarse a obtener la atención gubernamental para su tratamiento. Al desarrollarse más allá del gobierno y al involucrar tanto actores políticos como civiles, nos lleva a presentar dos subtipos analíticos dentro de la agenda sistémica: la "agenda no-gubernamental" defendida por los actores políticos con poder representativo pero que no forman parte del gobierno (se desenvuelven fundamentalmente en la arena parlamentaria) y la "agenda pública" defendida por los actores civiles y actores políticos sin poder representativo (se muestran desde afuera de las instituciones). Es importante destacar que independientemente de su origen nogubernamental o público, los problemas presentados desde la agenda sistémica, al no formar parte inicialmente de la agenda gubernamental, deberán obtener la atención del gobierno para no ser desechados y quedar sin tratamiento. Así pues, de todo lo dicho en este párrafo, se deriva que la "ventana de oportunidades" para que de un problema surja una política concreta para su resolución, puede atravesar diferentes trayectorias.

Por un lado, el gobierno (con control sobre la agenda gubernamental) cuenta con un mandato político que le otorga legitimidad para impulsar su programa. Ahora, esta puede no ser suficiente, si además requiere del consenso político (a nivel legislativo) para superar vetos parlamentarios, que dificulten la aprobación de la ley que implique la política pública. ${ }^{1}$ Ambos aspectos, legitimidad y poder político, son esenciales para todo gobierno con interés de efectivizar su agenda.

Por otro lado, el escenario es más complejo para los actores que no forman parte del gobierno, pero que también expresan problemáticas (agenda sistémica con origen nogubernamental o público). Estos requerirán, de otros factores para obtener el correspondiente apoyo político que impulse el tratamiento. Son dos los que consideramos esenciales para tal efecto. Un "contexto favorable" hacia la resolución de la problemática y la existencia de un marco de "acción colectiva" que la promueva. Como los individuos reflexionan y actúan dentro de un contexto socio-político determinado, si este último es favorable, tiene el efecto de brindarle relevancia y visibilidad pública. Por su parte, la generación de un marco de acción colectiva cohesionada, incrementa el consenso y la capacidad de presión sobre los formadores de la agenda gubernamental que quedarían negativamente expuestos de no brindar una respuesta (Keeler; 1993, Zahariadis; 2010).

\section{El voto femenino impulsado desde la agenda gubernamental}

\section{El problema: la universalidad restringida}

En 1912 se sancionó la "Ley Sáenz Peña” (Ley 8.871), la cual estableció el voto universal, secreto y obligatorio. No obstante, estos derechos y obligaciones no se dirigían a la 
totalidad de la ciudadanía sino a una parte, ya que la universalidad refería únicamente al género masculino. Esta decisión se vinculaba con la visión imperante del mundo, la cual presentaba una excluyente separación entre la esfera pública y la privada (atribuyéndose en cada una, funciones específicas a sus miembros). La primera se enlazaba con la arena política, quedando reservada a los hombres. La segunda estaba relacionada con la familia y los diferentes quehaceres del hogar, siendo las mujeres responsables de su cuidado (Gallo y Giacobone; 2001). De este modo, la Ley Sáenz Peña no hizo más que reproducir políticamente una situación ya existente en el escenario social. Pero esto no impidió la generación de voces críticas a la "universalidad" de la Ley 8.871. Las mismas, todas desde la agenda sistémica, se escucharon a nivel civil (agenda pública) y político (agenda no-gubernamental).

Mientras que los anarquistas consideraban la ausencia de derechos políticos para el género femenino como una legitimación de la organización autoritaria de la familia, Alicia Moreau de Justo fundamentaba su crítica en el desconocimiento y negación de la existencia política de la mujer (Moreau de Justo; 1945; Feijoó; 1982). Paralelamente, encontramos a Julieta Lanteri, quien en noviembre de 1911, previo a la sanción de la Ley Sáenz Peña, votó en las elecciones municipales de Buenos Aires, ante la ausencia de referencia alguna al sexo del votante en la convocatoria para la inscripción en el padrón. Desafiando el escenario imperante, también fundó el Partido Feminista Nacional e intentó presentarse como candidata a diputada nacional en 1919 (Bellota; 2001). A estas expresiones se sumaron organizaciones como la "Unión Feminista Nacional" o la "Asociación Pro-Derechos de la Mujer", que batallaban por una mayor igualdad de género (Gallo y Giacobone; 2001).

Si bien las organizaciones en defensa de los derechos de la mujer lograron avances en el ámbito civil con la reforma al Código Civil de 1926, no tuvieron el mismo resultado en el político. Y esto, a pesar de que el problema planteado (la ausencia de derechos políticos para la mujer) llegó a estar presente en la agenda no-gubernamental, pues algunos actores pertenecientes a la arena representativa no fueron ajenos (al menos, en lo discursivo) a las críticas a la Ley Sáenz Peña. De este modo, el Congreso Nacional fue testigo de la presentación de numerosos proyectos para brindar una solución al problema. Sin embargo, ninguno tuvo el consenso necesario para superar esta etapa y llegar a la "decisión" que transformara un proyecto en ley. ${ }^{2}$ La falta de acuerdo no solo refirió a una divergencia entre quienes estaban de acuerdo en otorgarle el derecho al voto a la mujer y quienes se oponían, sino también entre aquellos que se manifestaban favorables al cambio. En este punto, la disputa radicó en cómo concederle a la mujer la posibilidad de votar y presentarse como candidata. Muestra de esto lo encontramos en $1932,{ }^{3}$ momento en el que más cerca se estuvo de la sanción del voto femenino antes de la llegada del peronismo al poder (Ajmechet; 2012). El debate giró en torno a dos posiciones respecto al modo en que debían otorgarse los derechos a la mujer (la prime- 
ra defendida fundamentalmente por los socialistas y la segunda por los conservadores). Para los socialistas, no debía haber restricción alguna; para los conservadores, debía ser restringido y optativo. Si bien, la posición de los socialistas fue la que terminó primando en la Cámara de Diputados, la ausencia de un consenso mayor llevó a que el proyecto nunca fuera debatido en el Senado de la Nación (Palermo; 1998). De este modo, el tratamiento quedó en la nada, interrumpiéndose el proceso de política pública.

\section{La problemática en la agenda gubernamental: Perón en el poder}

Pese a lo anterior, las expresiones a favor del voto femenino continuaron vigentes, si bien hubo que esperar más de una década para que funcionarios del gobierno adoptaran como propia la problemática de la ausencia de derechos políticos para la mujer, con el fin de encontrarle una solución.

Ya como responsable de la Secretaría de Trabajo y Previsión del gobierno militar que accedió al poder en Junio de 1943, Juan Domingo Perón adoptó la estrategia de vincularse con actores de la escena social, instándolos a su organización y presentación de demandas frente al Estado (Torre; 1989, Romero; 1995). Así, buscó brindarles un orden que permitiese, al mismo tiempo, la construcción de una relación de fidelidad (Ajmechet; 2012). Las mujeres formaron parte de este acercamiento. Así lo demostró la creación en 1944 de la "Dirección de Trabajo y Asistencia de la Mujer" cuya función era promover la organización social y política del género femenino (Bianchi; 1986).

Tanto el movimiento obrero como los sectores defensores de los derechos de la mujer, decidieron aceptar el acercamiento oficial, ya que este manifestaba un escenario más favorable al encontrado hasta entonces, en términos de la presentación de demandas frente al Estado (Torre; 1989, Palermo; 2007). Pero esto no significó que el vínculo se transformase en subordinación; el voto femenino fue testigo de ello. Perón, en línea con su estrategia, había manifestado interés en el problema al que remitía su ausencia, ofreciendo como alternativa de solución el establecerlo mediante un decreto. Tal posibilidad no fue aceptada por las defensoras de los derechos de la mujer, quienes aspiraban a que surgiera por ley del parlamento (Barry; 2011). Sin embargo esta diferencia no derivó en un antagonismo irreconciliable entre Perón y las mujeres, pues gran parte del género femenino se inclinó hacia el liderazgo del primero, como lo manifestaron en la jornada del 17 de Octubre de 1945 y en la campaña presidencial de 1946.

Esta breve reseña histórica, es necesaria para comprender por qué una vez que Perón llegó a la presidencia en Junio de 1946, la problemática de la ausencia de derechos políticos para la mujer formó parte de su agenda gubernamental. El carácter central y jerárquico del voto femenino en el primer paquete de políticas impulsadas, lo encontramos explicitado en la inauguración del periodo de sesiones ordinarias del Congreso 
Nacional en aquel año, ya que Perón informó que impulsaría un proyecto para su tratamiento (Valobra; 2008).

Una vez explicitada la necesidad del tratamiento del problema, comenzó la campaña para su avance en términos del proceso de política pública, pues ahora era necesario que se presentaran y analizaran las alternativas de solución. Podemos decir que luego del discurso de Perón en el parlamento, encontramos dos grandes fuentes que impulsaron el tratamiento. Por un lado, la presentación de varios proyectos (con sus matices que analizaremos en la próxima sección) vinculados a la introducción del voto femenino. Por otro, la aparición de la figura de Eva Perón, quien capitalizó públicamente la campaña y la defensa por la incorporación política de la mujer mediante una serie de discursos radiales, donde remarcó el beneficio que tanto a nivel político como social significaría este hecho.

\section{El debate parlamentario: Implicancias y alternativas}

El debate parlamentario comenzó en la Cámara de Senadores el 21 de Agosto de 1946 y continuó camino hacia su sanción en la Cámara de Diputados el 9 de Septiembre de 1947. En ambas ocasiones la votación fue afirmativa. No presentaremos aquí una reseña lineal de los debates, sino un análisis de los mismos a partir de una serie de aspectos pensados desde la política pública: las implicancias del problema; las alternativas de resolución; finalmente, los efectos esperados de su posible solución.

\section{Implicancias del Problema:}

Uno de los aspectos centrales que surgió en el debate en torno a este punto, fue el vinculado a la democracia, pues varios legisladores hicieron hincapié en el hecho de que la ausencia de derechos políticos para la mujer ponía en tela de juicio el carácter democrático de la Argentina. Uno de ellos fue el Senador Lorenzo Soler:

¿Cómo podemos decir que somos profundamente democráticos si estamos negando a la mitad del pueblo, traducida en el sector femenino, la facultad y el derecho de participar en la vida integral de la democracia? Jamás podrá haber un pueblo democrático si no se incorpora a la otra mitad del género humano a la expresión de su libre voluntad (HSN 1946:38). ${ }^{4}$

Una opinión similar fue la del Diputado Manuel Graña Etcheverry:

Toda teoría restrictiva es, en su fondo, una teoría antidemocrática. La verdadera democracia se cumplirá cuando 
todos los habitantes del país, supuesta la suficiente instrucción que el Estado habrá de impartir, intervengan con perfecto conocimiento en los asuntos cívicos, sin distinción de sexos y sin más restricción de edades que las que surjan del referido mínimum de instrucción

(HCDN 1947:212). ${ }^{5}$

Un segundo factor presente en el debate fue la ausencia de reconocimiento del rol de la mujer en la vida en sociedad. El Senador Julio Herrera hizo hincapié en este punto, pues para él significaba una injusticia en tanto

La mujer, al igual que el hombre, es un factor esencial en la economía general de la Nación, y siendo así resulta inconcebible que ella no pueda participar en la vida política, que rige, precisamente, todo lo concerniente a la familia, a la educación, a la organización de los intereses económicos de esa misma sociedad

(HSN 1946:40).

En línea con este tópico, el Diputado Ángel Baulina hizo una referencia crítica tanto a características propias de la educación como a la existencia de una doble moral hacia el hombre y la mujer, siendo el voto femenino solo una parte del tratamiento necesario para superar estos hechos. En sus palabras:

...mientras los sistemas pedagógicos imperantes estén basados en el prejuicio de una moral doble, una para un sexo y otra para el otro, la mujer ha de estar colocada en una situación que no es la más conveniente para su educación política... En lo que refiere a los derechos políticos de la mujer no olvidemos que con el voto que le acordemos le daremos sólo un instrumento y es necesario llegar a la otra reforma más trascendental y que hace de una manera más precisa y directa a la vida del hogar: es el derecho de la mujer a igual retribución que los hombres cuando desempeñan las mismas funciones que ellos

(HCDN 1947:221).

\section{Alternativas de solución e implementación:}

Si bien el proyecto oficial y la mayoría de los alternativos (que diferían del oficial en cuestiones de forma) establecían que las mujeres pasarían a estar en igualdad de condiciones respecto al hombre en lo que respecta a los derechos y obligaciones políticas, en la Cámara de 
Diputados aparecieron dos propuestas diferentes respecto a esta cuestión puntual. La primera de ellas postuló que la inscripción al padrón de las mujeres mayores de 18 años no debía ser voluntaria, y que el voto femenino fuera optativo. El segundo establecía que aquellas que obtuvieran el derecho al voto serían no solo las que lo solicitasen sino también las que demostrasen cumplir con ciertas condiciones: ser mayor de dieciocho años, haber cursado sexto grado de la escuela elemental, no estar inhabilitada por cuestiones médicas, religiosas o jurídicas y estar dispuesta a prestar servicios auxiliares de defensa nacional.

En este diferendo respecto al carácter obligatorio u optativo del voto (con o sin condiciones adicionales), el oficialismo defendió su inclinación hacia la obligatoriedad sosteniendo la igualdad total en términos de derechos y obligaciones entre ambos géneros. El Diputado Graña Etcheverry lo expresó del siguiente modo:

...quiero dejar sentada la tesis del bloque mayoritario sobre la posición de la mujer en lo relativo a la emancipación femenina; la igualdad completa de derechos y obligaciones, con las salvedades dependientes de la diferencia de sexos, se infiere de la posición igualitaria de hombre $y$ mujer en el terreno del espíritu

(HCDN 1947:215)

Diferente fue el posicionamiento del Diputado Reynaldo Pastor, no en términos del otorgamiento del derecho al voto, sino en lo que respecta a su obligatoriedad. De acuerdo al argumento del legislador, este debía ser optativo:

Están las mujeres que desean vehementemente el ejercicio del derecho del voto, que siente la pasión del combate político, que siguen permanentemente todos los movimientos de nuestro partidos [...] Están las mujeres que repudian en lo intimo de su ser toda actividad política, que creen y tienen conciencia de que ese género de actividad les va a traer una preocupación perturbadora para su vida diaria $y$ para su tranquilidad, $y$ algunas hasta vislumbran peligros graves para la unidad de la familia y para la paz del hogar. Esas son las mujeres $-y$ son muchas- que no reclaman el derecho de ejercicio del voto, que no quieren ejercer ese derecho y que desean que si se sanciona una ley para satisfacer las aspiraciones muy legítimas de las que quieren el derecho de voto, no se le sancione con carácter obligatorio...

(HCDN 1947:222 y 223). 
Por su parte, el Diputado Miguel Petruzzi no solo defendió el carácter optativo sino también las condiciones adicionales que las mujeres debían cumplir para acceder al voto:

Dentro de la compleja actividad moderna, la actuación de la mujer complementa más que nunca y substituye, en gran parte, la del hombre... Es por eso que consideramos legítimo que la mujer aspire a ejercer los deberes $y$ derechos políticos, que por tradición siempre han correspondido al hombre. No obstante, considero que -momentáneamente- no puede imponerse a todas las misma obligación de cumplir con deberes políticos, siendo preferible que aquella que desee ejercer esos derechos y cumplir con los respectivos deberes lo solicite. Las restricciones pueden parecer un poco severas; pero aparte de ser educativas, son prudentes para una primera fase o etapa política...

(HCDN 1947: 245).

Este tipo de posicionamientos críticos hacia la obligatoriedad, tuvo respuestas de parte de aquellos que la defendían. Podemos mencionar dos ejemplos ilustrativos, en tanto muestran aspectos diferentes. Una de ellas fue la del Diputado Graña Etcheverry quien lo hizo desde la Constitución Nacional, al señalar que es un error considerar al voto solo como un derecho y no como una carga pública

Nuestras leyes, comenzando por la Constitución Nacional, asignan a la representación popular el carácter de una obligación a cargo de todos los habitantes del país

(HCDN 1947: 225).

Por su parte, el Diputado Eloy Camus, hizo una defensa de la obligatoriedad puntualizando que el voto optativo podía llevar a una inscripción discrecional de los votantes por parte de los gobernantes:

Yo le preguntaría al señor diputado por San Luis [Reynaldo Pastor] si ese sistema que él propugna no acarrearía el riesgo de que los gobiernos de provincia lo hagan optativo por fuerza, es decir que solamente inscriban a las que los gobernantes quieran inscribir y nieguen la inscripción en el registro a los adversarios políticos

(HCDN 1947:227). 
Finalmente analizaremos un punto interesante que surgió en el debate en términos de la implementación: el empadronamiento de las mujeres. Aspecto que se consideró podría generar demoras, no solo para que el voto femenino se torne efectivo sino también para la realización de las elecciones ya establecidas en el calendario. El Diputado Ángel Baulina fue uno de los legisladores que planteó este escollo y la necesidad de afrontarlo en la misma ley:

...paso a exponer los puntos que comprende el despacho de la minoría, que no constituyen precisamente una disidencia, sino que con ellos se quiere establecer perfectamente en la ley que se ha de sancionar que el otorgamiento de derechos electorales a la mujer no puede, por razones de dificultades que pudiera producir el enrolamiento femenino, ser obstáculo para la renovación normal y corriente de los poderes públicos. Por eso, en el artículo $6^{\circ}$ proyectado por la minoría se establece que los derechos de voto acordados a la mujer entrarán en vigencia una vez que esté terminado el padrón electoral femenino

(HCDN 1947:220).

El Diputado Pastor planteó un argumento similar al señalar que el empadronamiento debía aplazarse hasta mayo de 1948 (aspecto que incorporó el proyecto de minoría que él defendía) para evitar

...que tenga que realizarse todo el proceso de inscripción $y$ de formación del padrón electoral femenino en pleno período de un proceso electoral, como al que se verá abocado el país para el mes de marzo o abril. He querido que en ningún caso esta ley pueda servir para invocar la necesidad de diferir o de prorrogar los comicios de renovación de legisladores nacionales

(HCDN 1947: 228).

La defensa de la posición mayoritaria recayó en el Ministro del Interior Ángel Borlenghi:

...no está en el ánimo del Poder Ejecutivo confundir estas dos cosas: una, la elección corriente de diputados nacionales, que debe efectuarse de acuerdo con los plazos legales, y otra, el empadronamiento de las mujeres para que voten en el momento en que legalmente estén en condiciones de hacerlo

(HCDN 1947:244). 
De este modo, quedaba testimonio en el Parlamento de que el gobierno nacional no iba a interrumpir el calendario electoral por el empadronamiento de las mujeres y que éstas no votarían hasta tanto dicho proceso estuviera completo.

\section{Los efectos esperados de una posible solución:}

Un primer aspecto de acuerdo a los legisladores, sería la generación de un marco de igualdad política entre el hombre y la mujer. Nos parece interesante comenzar con las palabras del Senador Lorenzo Soler, en tanto para él, la formalización del voto femenino significaría un avance hacia dicha igualdad, porque

La mujer argentina se ha liberado y destacado en todas las actividades donde se le ha abierto las puertas para poner de manifiesto su capacidad de trabajo $y$ rendimiento...

(HSN 1946: 35).

En esta línea de análisis, el Diputado Graña Etcheverry indicó que

Algunos pronostican graves daños a la organización familiar, que sería abandonada - dicen - por causa de su participación en la lucha política. No quiero detenerme en este ni en otros argumentos parecidos. Sólo quiero advertir que nosotros partimos de un principio, en cuya virtud estructuramos la ley: el principio de la igualdad constitucional

(HCDN 1946:217 y 218).

El Diputado Baulina puntualizó:

En este problema de los derechos politicos de la mujer hay que distinguir dos situaciones distintas: uno es el derecho al sufragio, el derecho electoral, y otro es la vocación de la mujer para ser elegida en funciones públicas. Del examen de nuestra Constitución Nacional surge que no hay ninguna disposición que impida que el Parlamento argentino conceda a la mujer ambos derechos, el activo de ser elegida y el pasivo de elegir (HCDN 1947:218).

Este punto no es menor, pues la desigualdad había sido un elemento desde el cual se justificó la ausencia de los derechos políticos para la mujer. De hecho, voces dubitativas 
sobre la introducción del voto femenino, como la del Senador Armando Antille, usaron este tipo de argumentaciones para esgrimir su posicionamiento:

Yo no creo en absoluto que la mujer sea igual al hombre...La mujer ha nacido para realizar una función: la función maternal, nobilísima, a la que el hombre está ajeno. La mujer, por esa función que la naturaleza le ha dado, no ha venido a participar como el hombre en una vida de carácter social general."

(HSN 1946: 45). ${ }^{6}$

Un segundo aspecto en términos de los efectos esperados, fue el de la revitalización del sistema democrático, gracias a la introducción de un voto universal que involucrara al hombre y la mujer. Los Senadores Pablo Ramella y Julio Herrera explicitaron este punto al señalar respectivamente que

Cuanto más se extienda el número de los que puedan dar su opinión en las luchas políticas, más efectivo se hace el sufragio universal $y$, por lo tanto, la recta aplicación del sistema democrático de gobierno

(HSN 1946:30)

y que

Leyes como ésta, señor presidente, son conquistas de la democracia, porque la tornan más integral, más orgánica, más igualitaria, más económica, más humana

(HSN 1946:41).

En concordancia con la importancia de la inclusión de la mujer, vienen las palabras del Diputado Baulina, quien expresó:

Yo no tengo demasiadas esperanzas de que en un futuro próximo hemos de mejorar notablemente nuestras prácticas políticas. Creo sí que, acordando el voto a la mujer, acaso porque ella está amparada en el hogar y acaso porque entrará al goce de estos derechos con un sentido ético más elevado que el que ha dominado en el pasado nuestras luchas políticas, con todos sus episodios, algunas mejoras habremos de conquistar, que se han de trasuntar más que en el ejercicio 
del sufragio, en la acción legislativa de las primeras representantes femeninas

(HCDN 1947: 231).

La defensa de los derechos de la mujer en el ámbito público e institucional fue un tercer aspecto que obtuvo consideración. El Senador Ramella hizo mención al mismo, al precisar que

...si acordamos el voto a la mujer es casualmente para que use su voto en defensa de sus derechos de madre y de mujer, que indiscutiblemente sabrá defender con más tesón, con más perseverancia y con más altruismo que el hombre (HSN 1946:32).

En esta misma línea se expresó el Diputado Eduardo Rumbo:

Lo interesante, en un cuerpo colectivo como es el Congreso de la Nación, es la diversidad de experiencias. En este caso se sumaría, mediante la presencia de la mujer en el Parlamento argentino, una experiencia totalmente nueva, que conceptúo sería altamente beneficiosa para la legislación...

(HCDN 1947: 225).

\section{Decisión: igualdad de derechos y obligaciones para el hombre y la mujer}

La aprobación parlamentaria derivó en la promulgación de la Ley $\mathrm{N}^{\circ}$ 13.010. La misma estableció que las mujeres pasaban a tener los mismos derechos políticos (el de votar y el de poder presentarse como candidata a cargos representativos) y estar sujetas a las mismas obligaciones (acudir a votar en cada elección que se convoque en su distrito) que los hombres (art. 1), y equiparó el status de las mujeres extranjeras al de los hombres extranjeros en lo atinente a sus derechos políticos y las obligaciones (art. 2). Se creó el documento electoral ("libreta cívica") que debía entregarse a las mujeres con derecho al voto (art. 3) y se fijó el plazo máximo de dieciocho meses para el empadronamiento femenino por el Poder Ejecutivo (art. 4). La nueva ley eximió explícitamente a las mujeres de la obligación de prestar el servicio militar (art. 6).

\section{Implementación: desde elección nacional de 1951}

Desde la sanción de la ley hasta su primera implementación pasaron cuatro años. Fue recién el 11 de Noviembre del año 1951, que las mujeres pudieron acudir por primera vez 
a expresarse electoralmente. Las demoras en el empadronamiento y el aprovechamiento gubernamental del suceso histórico que significaba el voto femenino, obedecieron a variados motivos (Valobra; 2008, Barry; 2011).

En 1946 el padrón electoral había sido de 3.405.173 ciudadanos. En 1951 se incrementó a 8.613.998 individuos, ya que más de 4.000.000 de empadronados ahora eran mujeres. Estas acudieron de forma masiva a participar de su primer proceso electoral, con una participación superior al 90\% (Valobra; 2008). Vemos pues, que la incorporación de las mujeres a la vida política implicó un cambio sustancial en la cantidad de sujetos con derecho de influir en la vida democrática del país. Pero no solo en este aspecto se vio el impacto del voto femenino; también lo encontramos en la arena representativa. Ingresaron al Congreso Nacional las primeras parlamentarias: 23 en la Cámara de Diputados (15,4\% del total) y 6 en el Senado (20\%). Estas cifras aumentaron en 1955, con 34 diputadas (21,7\% del total) y 8 senadoras (22,2\%) (Marx, Borner y Caminotti; 2007). La puesta en práctica del voto femenino y el ingreso de mujeres al parlamento significaron un éxito en términos de los objetivos esperados. Sin embargo, como veremos a continuación, la introducción del voto femenino implicó, al mismo tiempo, la emergencia de un nuevo problema que tardaría décadas en encontrar una respuesta.

\section{Evaluación: Resultados positivos pero con una consecuencia inesperada}

La participación electoral femenina y la llegada de las mujeres al parlamento fueron muestra inicial del éxito en la intención de buscar una mayor igualdad entre el hombre y la mujer en la arena política. Al ser un derecho y una obligación el ir a votar, hizo de esta política pública una que no llegue a la etapa de la terminación, pues su implementación pasó a ser permanente en gobiernos civiles. Ponerle fin hubiera implicado eliminar el voto femenino.

Ahora bien, el resultado positivo fue apaciguado con el paso de los años por la emergencia de una consecuencia inesperada. De acuerdo a Nélida Archenti (2000), la igualdad instaurada por la Ley 13.010 terminó siendo formal más que real, debido a las desiguales posibilidades para el ingreso en los puestos representativos que las mujeres empezaron a experimentar frente a los hombres. Si bien entre 1951 y 1955 se incrementó la presencia femenina en las dos cámaras del Congreso Nacional, las décadas posteriores registraron valores menores. Los siguientes gráficos así lo ilustran. 


\section{Gráfico 1:}

Evolución del porcentaje de mujeres diputadas sobre total de la Cámara (1951-1975)

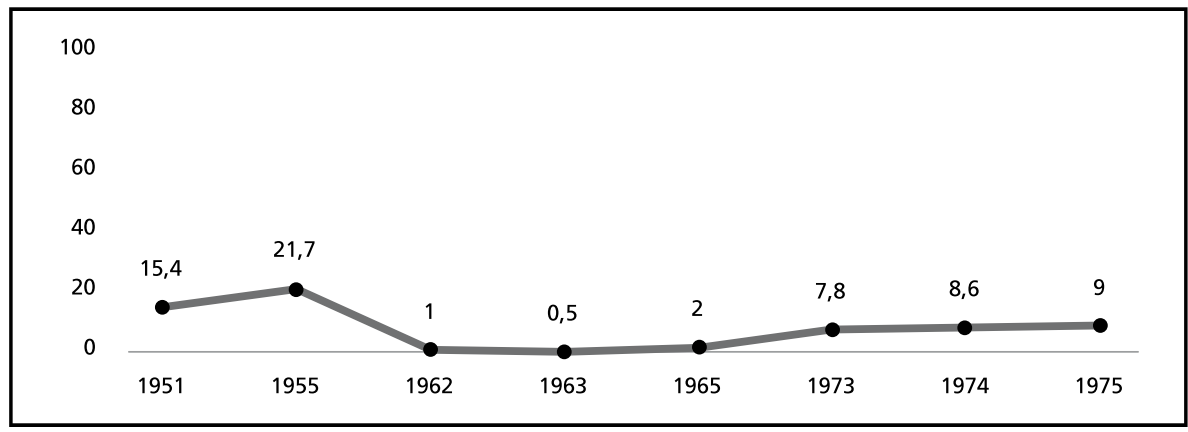

Fuente: Elaboración propia en función de datos en Marx, Borner y Caminotti (2007).

\section{Gráfico 2}

Evolución del porcentaje de mujeres senadoras sobre total de la Cámara (1951-1975)

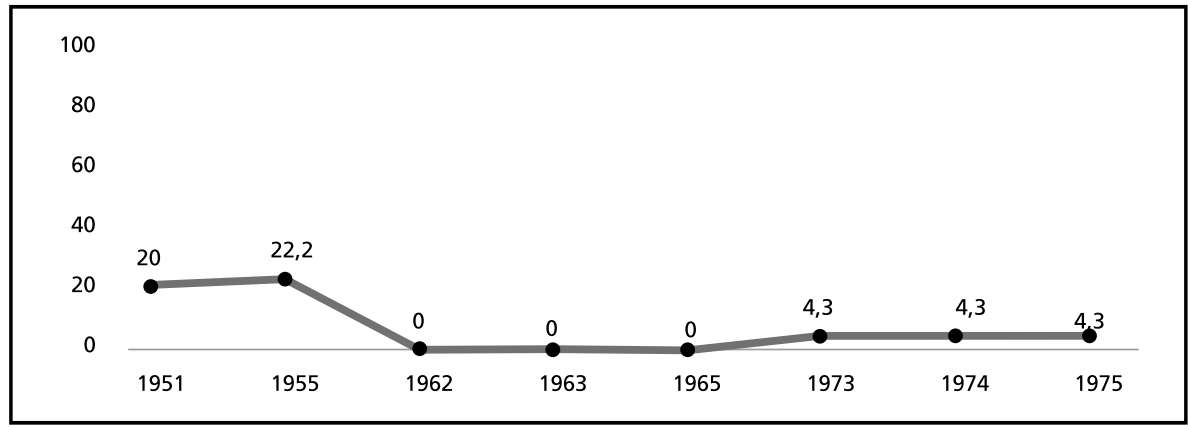

Fuente: Elaboración propia en función de datos en Marx, Borner y Caminotti (2007).

El persistente sesgo a favor de los hombres aportó la evidencia desde la cual comenzó a justificarse la existencia de una nueva problemática: la desigual posibilidad de ingreso a puestos representativos de la mujer respecto al hombre.

\section{Las cuotas impulsadas desde la agenda no-gubernamental}

\section{El problema: Una igualdad política incompleta entre el hombre y la mujer}

El regreso a la democracia en 1983, no manifestó un cambio favorable en la cantidad de mujeres en el parlamento. La Cámara de Diputados registró en aquel año una presencia femenina del 4,3\%, mientras que en el Senado fue del 6,5\% (Gallo y Giacobone; 2001). La persistencia en los partidos de la visión tradicional de que la política era una cuestión 
de hombres, ha sido un factor clave para que se genere esta situación (Archenti; 2000). Paralelamente, la atención del gobierno estaba focalizada en la consolidación democrática, lo cual dificultó que la problemática emergente fuera considerada desde la agenda gubernamental (Allegrone; 2002, Marx, Borner y Caminotti; 2007, Caminotti; 2009).

Pese a ello existieron voces críticas que se movilizaron en pos de resaltar la relevancia pública y política del problema. Estas expresiones tuvieron un origen plural ya que provinieron tanto de la arena política como civil. No obstante, compartían dos aspectos. Surgieron por fuera de la órbita gubernamental y su denuncia era homogénea en tanto refería a la ausencia de iguales condiciones para las mujeres respecto a los hombres en el ingreso a las listas de candidatos, que repercutía en su baja presencia parlamentaria. Se observa entonces que la manifestación del problema surgió desde ámbitos que no formaban parte del gobierno, sino desde actores no-gubernamentales y civiles. Como corolario, al expresarse desde la agenda sistémica, llevaba a la necesidad de obtener el reconocimiento gubernamental del problema para la búsqueda de una solución.

\section{La problemática desde la agenda sistémica: expresiones cívico-políticas}

A pesar de que el problema no formaba parte de la agenda gubernamental y los partidos políticos no manifestaban interés en incrementar la representación femenina en sus listas de candidatos, floreció en la década del ochenta un contexto favorable para que este obtuviera mayor visibilidad. Este escenario positivo remitía a un marco de mayor conciencia de género, debido a que con la apertura democrática surgieron factores que indicaban un rol más activo de la mujer (Gallo y Giacobone; 2001). Por un lado, encontramos la concreción de reivindicaciones civiles históricas, tales como la patria potestad compartida y la legalización del divorcio. Por otro, la creación de organismos como la "Multisectorial de la Mujer", el "Consejo Nacional de la Mujer" y la "Dirección de la Mujer". Finalmente, a los sucesos locales se le sumaba un contexto internacional también favorable; la "Convención de las Naciones Unidas sobre la Eliminación de todas las Formas de Discriminación contra la Mujer" y "Conferencia Mundial de la Mujer" llevada a cabo en Nairobi en 1985 son ejemplos de ello (Marx, Borner y Caminotti 2007; Caminotti 2009; Lopreite 2015).

Pero como la solución al problema no provendría del gobierno ni desde los partidos políticos, la introducción de alternativas de solución provino de la agenda no-gubernamental en consonancia con expresiones civiles a favor de las mismas. La introducción de la problemática en la agenda política no fue una iniciativa del gobierno, sino de un grupo de parlamentarias.

En noviembre 1989 se presentaron dos proyectos de ley de forma paralela que buscaban influir en la conformación de las listas de candidatos, teniendo en cuenta un principio 
de representación basado en las cuotas de género. Hablar de cuotas, significa que en un escenario donde no hay igualdad representativa, se introduce un mecanismo para alcanzarla (Hola,Veloso y Ruiz; 2002, Ríos y Villar; 2006, Jones; 2009). Para ello, los proyectos impulsaron "cuotas legislativas" que imponían a los partidos la obligatoriedad de llevar en sus listas un porcentaje determinado del género al que se quiere beneficiar (Krook; 2008). Mientras que el primer proyecto estipulaba un mínimo de $30 \%$ de mujeres, el segundo sostenía que no podía haber en la lista más de un 70 \% de personas del mismo sexo. ${ }^{7}$

El siguiente paso fue conquistar la atención del gobierno si se pretendía incrementar las chances de continuar con el proceso de política pública. Con el fin de generar ese avance, se desplegó en la arena civil una estrategia para incentivar el conocimiento de la situación y el consenso hacia los proyectos. Al respaldo expresado por la "Multisectorial de la Mujer", se le sumó la constitución de la "Red de Feministas Políticas", organización que defendía la incorporación de las cuotas, argumentando que el aumento de mujeres en el Parlamento mejoraría cualitativamente la política (Archenti y Tula; 2008). También se realizó el " 5 Encuentro Nacional de Mujeres" desde donde se enviaron misivas a los líderes partidarios y parlamentarios, insistiendo sobre la importancia de la medida. Todas estas acciones no solo acrecentaron la visibilidad pública, sino que también tuvieron un efecto positivo en la arena gubernamental, al obtener finalmente el respaldo del Presidente de la Nación, Carlos Menem (1989-1999).

\section{Debate parlamentario: Implicancias y alternativas}

El debate parlamentario se desarrolló en la Cámara de Senadores los días 20 y 21 de Septiembre de 1990, y en la de Diputados el 6 y 7 de Noviembre de 1991. En ambos recintos la votación fue positiva para la incorporación de las cuotas. Del mismo modo que lo hicimos con el voto femenino, aquí presentaremos algunos fragmentos del debate,${ }^{8}$ con el fin de mostrar el posicionamiento de los legisladores.

\section{Implicancias del problema:}

Para los legisladores, la consecuencia central del problema era la discriminación política (en términos del acceso a cargos representativos) de la mujer. En esta línea se expresó el Senador Luis Brasesco

... a pesar de que la mujer ejerce el voto $y$ de que puede ser electa, debemos también tener en cuenta una realidad clara y concreta. No quiero emplear la palabra "machista" pero, indudablemente, la concepción tradicional y conservadora de quienes nos hemos acostumbrado a vivir permanentemente en el quehacer político revela que hemos sido tozudos y, quizás, poco generosos para crear reglas 
equitativas $y$ justas que permitan a la mujer integrar las listas para estar presentes en los parlamentos

(HSN 1990:49).

La Senadora Margarita Malharro de Torres y la Diputada Inés Botella se remitieron a los partidos políticos como organizaciones responsables de esta situación. La primera señaló que

Los partidos políticos se abren para amontonar mujeres que trabajen en las campañas electorales, para amontonar mujeres al pie de la tribuna y que el candidato pueda decir lo que va a hacer con ellas. Pero no empiezan a hacer desde el vamos lo fundamental, que es abrirles las puertas para que entren y se jerarquicen políticamente, integrando las listas de candidatos

(HSN 1990:60).

La segunda indicó que las mujeres

Conformamos el 59 por ciento del padrón electoral, pero como representantes políticas sólo alcanzamos un 3 por ciento. Ésta es una situación de absoluta injusticia. Si bien somos muchas, parece que cuando a las 4 o 5 de la madrugada los hombres confeccionan las listas electorales -no digo que por maldad o por una cuestión de machismo- no tienen tiempo de acordarse de las compañeras militantes que tenemos igual capacidad para desempeñarnos...

(HCDN 1991:74 y 75).

No todos los legisladores manifestaron acuerdo con dicha lectura. El Senador Libardo Nicolás Sánchez sentenció que el problema mencionado no existía en la realidad argentina:

... yo creo que este proyecto es más una expresión de anhelo para todas las mujeres sometidas en diversos lugares del globo, que no encaja con la realidad argentina porque hace mucho tiempo en la vida del país la mujer argentina - para buscar un término adecuado- legalizó su presencia natural en la vida de la Nación

(HSN 1990:52). 
De este modo, para el senador, la ausencia de mujeres en el parlamento era voluntaria:

Que muchas veces no haya una distribución igualitaria en el momento de la confección de las listas de candidaturas obedece $-y$ téngase presente, para dignificar aún más la postura de la mujer- a que en nuestro partido, por ejemplo, las mujeres resignan voluntariamente cargos políticos en un acto de conciencia, en el que han expresado que no estaban capacitadas para ocupar tal o cual cargo, lo que más las enaltece.

(HSN 1990: 53).

\section{Alternativas de solución e implementación:}

En lo que respecta a las alternativas, durante el debate además de la defensa de la discriminación positiva generada por las cuotas, se manifestaron expresiones a favor de realizar cambios sustantivos al proyecto bajo tratamiento.

Los legisladores que defendieron la importancia de introducir las cuotas de género, lo hicieron desde la consideración de que se estaba ante una herramienta institucional con la capacidad de incrementar la representación femenina. La Diputada Marta Martín de De Nardo, al presentar el 30\% como un piso mínimo, sostuvo:

Se dice que este proyecto es discriminatorio y efectivamente lo es. Pero es una discriminación positiva y protectora. También es una discriminación necesaria, porque si desde el Estado no se exigiese la participación femenina en las listas a cargos electivos, esa participación seguiría siendo un derecho ilusorio

(HCDN 1991:84 y 85).

La Diputada Inés Botella, justificó la importancia de la vía legislativa para introducir las cuotas debido a la ausencia de prácticas equitativas en los partidos políticos:

Los partidos políticos aquí representados - que por algo adelantaron su voto- no pueden negar que podrían confeccionar listas de candidatos integradas en un ciento por ciento por mujeres tan o más capaces, sensibles e inteligentes que las que estamos aquí sentadas. Desgraciadamente, cuando a las mujeres se nos pide capacidad y excelencia, en realidad se nos está exigiendo tres veces más de capacidad que a los hombres y quizás cinco veces más de exce- 
lencia... agotada toda otra vía, se recurrirá a la legislativa para implementar lo que se llama discriminación positiva, de modo que las mujeres vayan ganando lugares de participación en la vida política y social del país

(HCDN 1991: 75).

En el debate también surgieron inquietudes y propuestas de modificación. El Senador Oraldo Britos consideró que el proyecto era discriminatorio

...según la Constitución Nacional para participar, para ser diputada, concejal o gobernante, la única condición necesaria es la de tener idoneidad. Pero ahora queremos crear una nueva figura. Yo no soy abogado, pero tengo miedo de que, después, mis compañeros de la rama gremial también vayan a solicitar una inserción o una participación; que luego vengan los maestros y las maestras $y$ no digan que, por lo menos, el 25 por ciento de ellos deben figurar en las listas

(HSN 1990:68). ${ }^{9}$

Otra observación fue la realizada por el Diputado Luis Zamora, que habría de retomarse luego de las primeras implementaciones de la ley. De acuerdo al legislador el proyecto, tal como estaba redactado, podía ser burlado:

El proyecto dice: "Las listas que se presenten deberán tener mujeres en un mínimo del 30 por ciento de los candidatos a los cargos a elegir y en proporciones con posibilidad de resultar electas” ¿Quién decidirá si existe esa posibilidad? ¿Es una posibilidad formal? Obsérvese que no dice "probabilidad" sino "posibilidad". Cualquiera podrá decir: "todos los que se presentan tienen posibilidad, depende de los votos que se obtengan

(HCDN 1991:93).

Se presentaron algunas propuestas de modificación, que no fueron aceptadas. El Diputado Héctor Seguí, por ejemplo, hizo hincapié en la tarea del juez electoral de no oficializar toda aquella lista que no cumpliera el piso de las cuotas (objeción formulada también por otros legisladores durante el debate en particular en la Cámara de Diputados). La razón estaba, a juicio del diputado, en el grado de "interpretación" que se le podía atribuir al juez en términos de la satisfacción (o no) de la cuota: 
Cuando hablamos del 30 por ciento todos pensamos en términos aritméticos, pero en realidad se produce un avance geométrico, ya que el 30 por ciento de tres es 0,9 , lo cual se transforma en un legislador. En el caso de distritos más grandes a los que les corresponden seis diputados, el 30 por ciento es 1,8 , lo que da un total de dos del sexo femenino, y ello ocurrirá en las sucesivas renovaciones. ¿Cuál será el criterio del juez electoral de la Capital Federal? No deseo nombrar partidos, pero debo señalar que cuando se presente la lista de la Unión Cívica Radical, de seis candidatos habrá que elegir dos, que pueden ser los primeros, los del medio o los últimos Algo similar puede ocurrir con el justicialismo ¿Quién le indicará al juez cuáles son los candidatos en condiciones de ser electos?

(HCDN 1991:81).

Como corolario, el diputado propuso eliminar esta disposición del proyecto que llevaba al juez electoral a oficializar o no una lista de candidatos. Paralelamente, este diputado, al igual que lo hiciera el Senador Emilio Tomás, propuso, sin fundamentarla, modificar el porcentaje de las cuotas al $50 \%$ de mujeres. La respuesta ofrecida a estas demandas (esgrimida por el Diputado Raúl Álvarez Echagüe) fue la de no modificar nada en aquel momento con el fin de que se sancione la ley.

\section{Los efectos esperados de una posible solución:}

Un primer aspecto es la mejoría en la democracia. Esto se desprende de las palabras de la Senadora Malharro de Torres

Esta iniciativa no pertenece a cincuenta, sesenta o setenta personas; pertenece a cientos de mujeres argentinas que hoy están pendientes de este parlamento; están pendientes de que en este senado, esta noche se dé el paso adelantado, moderno, "aggiornando", de incorporar, transitoriamente, por cupo, a la mujer para que acceda a los poderes legislativos, fundamentalmente, como le corresponde... Queríamos que en este país, que ya está viviendo el tiempo electoral, sepan las mujeres quiénes les tienden la mano para que, con justicia, tomen su lugar definitivo en la democracia (HSN 1990: 58 y 59). 
Su colega el Senador Hipólito Solari Yrigoyen remarcó que con la medida debía superarse la ausencia de prácticas igualitarias en los partidos

...el desiderátum debería ser que los partidos políticos, por su propia voluntad y juego interno, alternaran en sus listas a hombres y mujeres en forma equilibrada. Porque ambos sexos tienen las mismas aptitudes para ocupar este tipo de funciones. Pero esa es una utopía, porque en la realidad no se da tal situación. Por esa razón me parece que corresponde establecer un mínimo de representación... hasta que las prácticas de civilización política nos lleven al desiderátum

(HSN 1990: 50).

También surgió la esperanza en el carácter transitorio de la medida, fruto del anhelo de que en un futuro se llegase a la etapa de la "terminación", gracias a un avance cultural que hiciera innecesario el acudir a las cuotas. La Senadora Malharro de Torres expresó en este sentido que

Llegará el día en que no será necesario establecer representaciones mínimas de la mujer. Ese día será el de las sociedades transparentes, libres $y$ sin prejuicios

(HSN 1990: 62).

Finalmente, podemos citar a la Diputada Ruth Monjardín de Masci, pues creemos que su posición resume el sentido del carácter transitorio:

Ojalá que en el futuro los diputados que se sienten en estas bancas digan que ya no hace falta la ley. El día que digan eso será porque gracias a esta ley educadora, quizá un poco autoritaria, se habrá incorporado a la mentalidad de los dirigentes de todos los partidos políticos, a la de las mujeres-que a veces no se animan a participar- $y$ en general a la cultura del pueblo argentino, el concepto de que es una pena que no puedan llegar a ocupar una banca en este recinto tantas mujeres capaces, nobles, talentosas $y$ abnegadas, que son médicas, como dijo el señor diputado Cruchaga, asistentes sociales, maestras, obreras y tanto más madres que viven con dignidad su vida aún en una villa miseria. Es mi deseo que se acepte y se convierta en una conducta y en una costumbre la posibilidad de que 
en la República Argentina todos esos miles de mujeres puedan ocupar una banca en este cuerpo

(HCDN 1991:91).

\section{Decisión: Un 30\% de mujeres en la lista de candidatos nacionales}

La aprobación parlamentaria llevó a la sanción de la Ley 24012. El contenido sustantivo de la misma se encuentra en su artículo primero que sustituyó al artículo 60 del decreto 2135/83 (Código Electoral Nacional), referido al "Registro de candidatos y pedido de oficialización de listas”. Originalmente, dicho artículo indicaba que los partidos debían informar sus candidatos en el periodo que va desde la convocatoria a la elección hasta cincuenta días antes de la misma. Con la nueva ley los partidos políticos debían contemplar la presencia de al menos un 30\% de mujeres en "proporciones con posibilidad de resultar electas", al comunicar la lista de postulantes. De no cumplir con esta cuota, la lista no sería oficializada.

Posteriormente el decreto reglamentario 379/93 precisó la finalidad de la Ley 24.012:

lograr la integración efectiva de la mujer en la actividad política evitando su postergación al no incluirse candidatos femeninos entre los candidatos con expectativa de resultar electos. ${ }^{10}$

\section{Implementación: Elecciones a diputados y senadores nacionales}

El año 1993 significó para la Cámara de Diputados de la Nación la primera elección con la implementación de las cuotas. Por su parte, la Cámara de Senadores de la Nación experimentó el mismo proceso en el 2001, cuando la elección de senadores pasó a ser directa. Desde entonces y hasta la fecha, la Ley de Cuotas ha continuado vigente.

El impacto del nuevo marco legal significó un incremento de la presencia femenina en ambas cámaras. Nótese el punto de inflexión que representó la primera implementación (1993 para diputados y 2001 para senadores) ${ }^{11}$ y la evolución que desde entonces ha tenido dicha presencia. 


\section{Gráfico 3:}

Evolución del porcentaje de mujeres diputadas en el total de la Cámara (1983-2013)

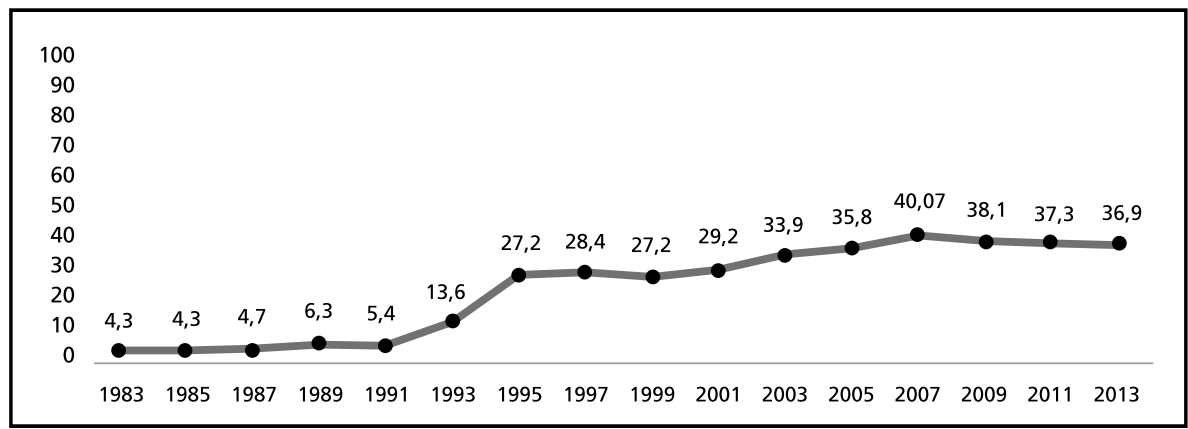

Fuente: Elaboración propia en función de datos del Ministerio del Interior de la Nación.

\section{Gráfico 4:}

Evolución del porcentaje de mujeres senadoras en el total de la Cámara (1983-2013)

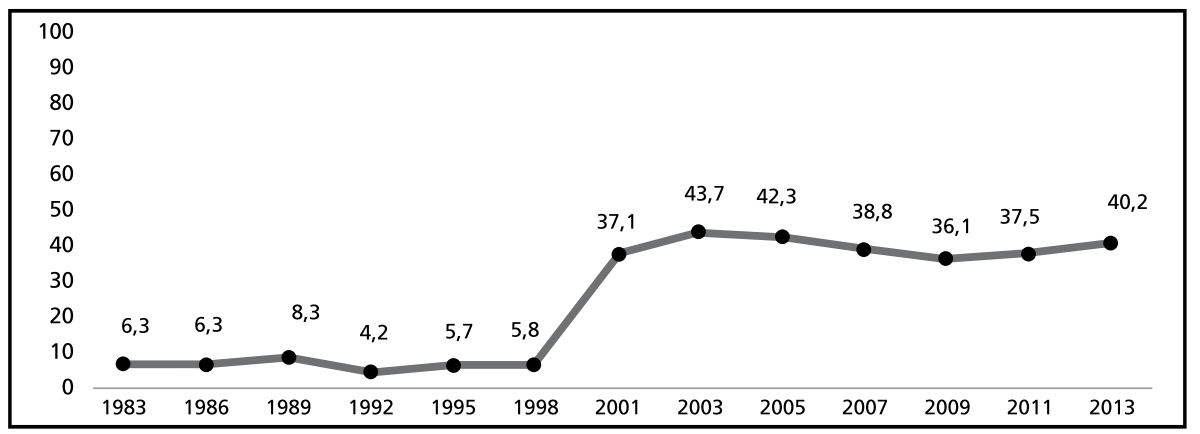

Fuente: Elaboración propia en función de datos del Ministerio del Interior de la Nación

A pesar del incremento de la representación femenina, surgieron expresiones críticas respecto al modo en que los partidos políticos se habían amoldado a la Ley de Cuotas y su decreto reglamentario. Esto fue así porque esas agrupaciones incorporaron el 30\% de mujeres, pero desde una óptica controversial al ubicarlas en los últimos lugares. Esto significaba partir del supuesto de que las candidaturas con posibilidades de ser electas debían contemplar la totalidad de los cargos, ya que un partido podía ganar todas las bancas (Tula 2002; Marx, Borner y Caminotti; 2007).

\section{Evaluación crítica y modificaciones}

Dicha situación, experimentada en 1993 y en elecciones posteriores, generó presentaciones judiciales de candidatas perjudicadas (Tula 2002). Paralelamente, la reforma constitucional de 1994 jerarquizó las cuotas al incluirlas en la Constitución Nacional (art. 
37).$^{12}$ Esta jerarquización no resolvió el conflicto, pero hizo posible que la Cámara Nacional Electoral autorizara al Consejo Nacional de la Mujer a sumarse a las demandas de candidatas damnificadas, con el fin de generar el cumplimiento efectivo de las cuotas.

En el decreto reglamentario 1246/2000, que reemplazó al original (379/93), encontramos una primera respuesta gubernamental a la ausencia de un criterio común en la implementación de las cuotas. El objetivo fue unificar el procedimiento que debía seguirse para una adecuada ubicación de las mujeres en las listas, siempre teniendo como base mínima el 30\% requerido por la ley. Para tal fin se modificó el cálculo cuando el porcentaje determinase fracciones menores a la unidad. ${ }^{13}$ También precisó que, aunque es indiferente iniciar la lista con un candidato hombre o mujer, la segunda ubicación deberá ser ocupada por una persona del sexo opuesto. En caso de renovarse dos cargos, en uno de ellos deberá nominarse siempre a una mujer y en caso de renovarse más de dos, debe figurar al menos una mujer en uno de los tres primeros lugares, especificándose que no se considerará cumplida la norma cuando en los casos donde en la renovación de uno o dos cargos se incluya una mujer en el tercer término. Cuando se renueven uno, dos o más cargos, el cómputo siempre se hará desde el primer lugar, debiendo tener la lista por lo menos una mujer por cada dos varones. Paralelamente, se indica que en la lista no se podrá ubicar de forma contigua a tres personas del mismo sexo, hasta tanto no se haya cumplido el 30\%. En caso de fallecimiento, incapacidad o cese en la candidatura con anterioridad a la elección pero después de oficializada la lista, su lugar deberá ser ocupado por la candidata que le siga en la lista. Finalmente, se reconoce el derecho de toda persona incluida en el padrón electoral, a impugnar ante la Justicia Electoral las listas que se considere no cumplen la cuota mínima.

Este decreto fue posteriormente reformado por el 451/2005. De acuerdo al nuevo texto, el Decreto 1246/2000 al fijar las pautas para la aplicación efectiva de esa norma legal, contrarió su espíritu, al establecer la alternancia de los sexos en la conformación de las citadas listas, transformando en máximo, el porcentual mínimo. En consecuencia dispuso que cuando algún partido, confederación o alianza, se presentara por primera vez, no renovara ningún cargo o renovara uno o dos cargos, en uno de los dos primeros lugares de la lista deberá nominarse siempre "como mínimo" una mujer. Paralelamente, se eliminó la condición de que independientemente de si sea mujer o varón quien vaya primero en la lista, el segundo debe ser para una persona del sexo opuesto. Asimismo se modificó el decreto anterior en el sentido que cuando se renueve uno, dos o más cargos, el cómputo de las cuotas debe iniciarse en el primer lugar de la lista, ubicándose "por lo menos" una mujer cada dos varones. Al mismo tiempo, se suprimió de la imposibilidad de ubicar en forma contigua tres personas del mismo sexo.

Si bien todas estas modificaciones impulsadas luego de la Ley 24012 tuvieron la intención de asegurar una adecuada implementación de las cuotas, podemos rastrear una 
segunda línea de evaluación crítica procedente de la literatura especializada. Esta mirada se vincula con lo partidario.

Aunque se registró un incremento cuantitativo de mujeres en el parlamento, el nivel alcanzado es similar al porcentaje mínimo estipulado por las cuotas, lo cual sugiere que dicho avance no ha ido mucho más allá del "efecto mecánico" de la legislación (Caminotti, Rotman y Varetto; 2014). De acuerdo a Archenti y Tula (2008) las cuotas no flexibilizaron las estructuras de poder en los partidos políticos, que siguieron siendo discriminatorias hacia las mujeres. Estas mismas autores sostienen que tal situación derivó en una "interpretación minimalista" de las cuotas, implicando que el "porcentaje mínimo" se transforme en realidad en un techo. De este modo, la Ley 24.012 y los decretos sucesivos, se transformaron en una "obligación molesta" que los líderes partidarios debían cumplir (pudiendo hacerlo en términos estrictos sin ir más lejos de lo estipulado formalmente) para evitar que las listas no fueran aceptadas por la justicia (Borner, Caminotti, Marx y Rodríguez Gustá 2009; Johnson 2014).

Lo anterior nos lleva a nuestra última reflexión, vinculada con la continuidad de esta política pública. Aceptando el argumento que hemos señalado en el párrafo anterior, podemos llegar a la conclusión de que el cambio cultural esperado por varios legisladores durante el debate, el cual debía llevar a la inutilidad de las cuotas, hasta el momento no se ha efectivizado. Si las organizaciones partidarias han tendido a reproducir una estructura de poder centrada en los hombres, perjudicando el crecimiento político del género femenino, se entiende la razón del no arribo a la etapa de la terminación. De este modo y para finalizar, la relevancia que ha obtenido la continuidad de la implementación de las cuotas, la podemos graficar con la siguiente pregunta hipotética ¿Qué sucedería con el nivel de representación femenina si la Ley 24.012 fuera derogada?

\section{Conclusiones}

Este trabajo ofreció un análisis de política pública del proceso de democratización de la representación en la Argentina, con el otorgamiento de los derechos políticos a la mujer. El haber utilizado el modelo secuencial de políticas públicas, nos permitió dividir dicho proceso en dos momentos, pues cada uno de ellos se activó ante problemas específicos. El primero, del cual surgió el voto femenino, respondió a la problemática de la universalidad restringida, pues con anterioridad, solo los hombres podían expresarse políticamente. El segundo, relacionado con las cuotas de género, actuó ya en un escenario de igualdad formal aunque no real, debido a la ausencia de prácticas equitativas entre el hombre y la mujer para acceder a cargos representativos.

De lo anterior, se desprende un punto interesante que hemos intentado remarcar en la exposición: la conexión entre los dos casos estudiados. Si bien cada uno fue fruto de 
una problemática particular, la vinculada con las cuotas surgió con los resultados de la implementación del voto femenino. Es decir, la evaluación de esta última implicó un éxito en la participación electoral, pero progresivamente manifestó una consecuencia inesperada en la baja presencia parlamentaria femenina, aspecto que habría de derivar en la introducción de las cuotas de género. Por lo tanto, este hecho nos permite reforzar la idea del carácter no solo dinámico sino también circular del proceso de política pública. Esto así pues las consecuencias inesperadas de la implementación pueden reactivar las primeras etapas referentes al planteo del problema, la agenda, la discusión, la decisión y nuevamente, la implementación.

Finalmente, que sea circular, también nos permite suponer que hemos estado analizando un proceso que no ha finalizado sino que sigue vigente. Hemos señalado en este sentido algunas de las críticas formuladas a los partidos políticos respecto al modo en que cumplen con los requisitos de la normativa. De este modo, la aún escasa presencia femenina en el parlamento (menor al 50\%) puede ser motivo en el futuro para retomar las primeras etapas del proceso de política pública para su tratamiento. 
${ }^{1}$ Partimos del supuesto de que se impulsan políticas legalmente viables. Por eso es que no mencionamos la legalidad de la medida como condición.

${ }^{2}$ El primero de esos proyectos data de 1919, presentado por el diputado Rogelio Araya. Desde entonces, se presentaron diversos proyectos en ambas cámaras del Congreso Nacional.

${ }^{3} \mathrm{El}$ proyecto fue ingresado a la Cámara de Diputados, siendo su autor el Diputado Alfredo Palacios.

${ }^{4}$ Honorable Senado de la Nación.

${ }^{5}$ Honorable Cámara de Diputados de la Nación.

${ }^{6}$ El Senador Antille originalmente pidió que se pospusiera el debate pues no se encontraba seguro sobre su posicionamiento. Finalmente, luego del pedido expresado por sus colegas senadores, decidió quitar su reclamo de aplazamiento.

${ }^{7}$ El primero fue presentado por la senadora radical Margarita Malharro de Torres. Siendo este el que fue tratado a nivel parlamentario. El segundo fue introducido por un grupo multipartidario de diputadas nacionales: Norma Allegrone de Fonte, Florentina Gómez Miranda y Blanca Macedo de Gómez de la Unión Cívica Radical; Matilde Fernández de Quarracino de la Democracia Cristiana; Ruth Monjardín del Partido Federal; Inés Botella del Partido Justicialista (Marx, Borner y Caminotti 2007).

${ }^{8}$ La fuente utilizada para acceder al debate es Gallo y Giacobone (2001).

${ }^{9}$ Esta posición fue respondida por la Senadora Margarita Malharro de Torres al señalar que "Los padrones electorales son de hombres y mujeres. No hay padrones de maestras, por ejemplo." (HCS 1990:69).

${ }^{10} \mathrm{El}$ decreto reglamentario precisó que el cupo del 30\% debía ser debía ser interpretado como un porcentaje mínimo. En los casos donde el porcentaje determinara fracciones menores a la unidad, el concepto de cantidad mínima quedaría determinado del modo que ejemplificamos a continuación: cuando hay ocho cargos a renovar, el $30 \%$ refiere a 2,40\% de cargos; en este caso serán 2 cargos como cantidad mínima de mujeres. Pero si son nueve los cargos a renovar, el 30\% se transforma en 2,70\%, serán 3 cargos a renovar. El decreto definió como ámbito de aplicación la totalidad de los cargos electivos parlamentarios nacionales y los vinculados con los concejales y los consejeros vecinales de la (entonces) Municipalidad de Buenos Aires. Estableció que el porcentaje mínimo requerido, se consideraría cumplido cuando el mismo alcance la totalidad de candidatos de la lista, siendo indiferente comenzar la lista de candidatos con un hombre o una mujer, pero en los siguientes lugares deberá incorporarse una mujer por cada dos hombres hasta cubrir el porcentaje mínimo exigido. En caso de renovarse dos cargos al menos uno de los candidatos propuestos debe ser una mujer (art. 5).

${ }^{11}$ Cabe destacarse, que en 1993 la renovación en la Cámara de Diputados fue parcial mientras que en 2001 la renovación en el Senado fue total debido a que, fruto de la reforma constitucional de 1994, comenzó a implementarse el sistema de elección directa de senadores. De acuerdo a Marx, Borner y Caminotti (2007) este es uno de los factores explicativos para entender la razón de que la representación femenina alcanzara solo el 13,6\% en la Cámara de Diputados en 1993. El segundo, que lo desarrollaremos en la evaluación, se vincula con el relegamiento de las mujeres a posiciones de las listas con pocas posibilidades de resultar electas. ${ }^{12}$ Según este artículo "la igualdad real de oportunidades entre varones y mujeres para el acceso a cargos electivos y partidarios se garantizará por acciones positivas en la regulación de los partidos políticos y en el régimen electoral".

${ }^{13}$ Ahora, la cantidad mínima sería la unidad superior. En otros términos, la unidad menor a 0,5 y la unidad mayor a 0,5 decantará siempre hacia el valor mayor. Siguiendo con el mismo ejemplo analizado anteriormente, con ocho (donde el $30 \%$ refiere a $2,40 \%$ ) y nueve candidaturas (donde el $30 \%$ refiere al 2,70\%), la cuota mínima pasa a ser tres. 


\section{Referencias Bibliográficas}

Aguilar Villanueva, Luis (1993), Problemas Públicos y Agenda de Gobierno, México: Porrúa.

Ajmechet, Sabrina (2012) "El peronismo como momento de reformas (1946-1955)". Revista SAAP 6 (2): 249-266.

Allegrone, Norma (2002) Ley de cupo femenino: Su aplicación e interpretación en la República Argentina, Buenos Aires: Fundación para el desarrollo e igualdad, FUNDAI/ Fundación Friedrich Ebert.

Anderson, James E. (1997) Public policymaking, Boston: Hougton Mifflin Company.

Archenti, Nélida (2000) "Representación, Ley de Cuotas y Sistemas electorales". PostData 6, 171-194.

Archenti, Nélida y María Inés Tula, (2007) "Los limites institucionales de las cuotas de género en América Latina”. Revista Iberoamericana VII (27), 184-190.

Archenti, Nélida y María Inés Tula, (2008) Mujeres y política en América Latina. Sistemas electorales y cuotas de género, Buenos Aires: Heliasta.

Barry, Carolina (2011) “Eva Perón y la organización política de las mujeres.” Documento de trabajo. Universidad del CEMA, Buenos Aires.

Bellota, Araceli (2001) Julieta Lanteri. La pasión de una mujer, Buenos Aires: Planeta.

Bianchi, Susana (1986) "Peronismo y sufragio femenino: la ley electoral de 1947". Anuario IEHS No 1, 255-296.

Borner, Jutta; Mariana Caminotti, Jutta Marx y Ana Laura Rodríguez Gustá, (2009) Ideas, presencia y jerarquías políticas. Claroscuros de la igualdad de género en el Congreso de la Nación de Argentina, Buenos Aires: Prometeo.

Caminotti, Mariana (2009) En el nombre de la Democracia. La invención del cupo femenino y la difusión de cuotas electorales en la Argentina, tesis de doctorado en Ciencia Política por la Universidad de San Martín. Directora: Ana Laura Rodríguez Gustá. 
Caminotti, Mariana; Santiago Rotman y Carlos Varetto, (2014) “Desigualdades persistentes: una mirada a las carreras políticas subnacionales antes y después de las cuotas de género (Argentina, 1983-2011)" en Nélida Archenti y María Inés Tula (coordinadoras) La representación imperfecta. Logros y desafíos de las mujeres políticas, Buenos Aires: Eudeba, 201-214.

Cobb, Roger y Charles Elder, (1984) “Agenda-building and The Politics of Aging”. Policy Science Journal 1 (13), 115-129.

Feijoó, María del Carmen (1982) Las feministas, Buenos Aires: CEAL.

Gallo, Edit R. y Carlos A. Giacobone (2001) Cupo femenino en la política Argentina, Buenos Aires: Eudeba.

Hola, Eugenia; Paulina Veloso y Carolina Ruiz, (2002) “Percepciones de los líderes políticos y sociales sobre la ley de cuotas: contenidos y factibilidad”, Departamento de estudio y estadística del Servicio Nacional de la Mujer. Documento de trabajo N 79.

Jones, Mark (2009) “Gender Quotas, Electoral Laws and the Election of Women: Evidence From the Latin American Vanguard". Comparative Political Studies 42 (1), 56-81.

Johnson, Niki (2014) "Las barreras que la cuota no superó: selección de candidaturas y desigualdades de género en América Latina” en Nélida Archenti y María Inés Tula (coordinadoras) La representación imperfecta. Logros y desafíos de las mujeres políticas, Buenos Aires: Eudeba, 37-61.

Keeler, John (1993) "Opening the Window for Reform. Mandates, Crises and Extraordinary Policimaking”. Comparative Political Studies 25 (4), 433-486.

Kingdon, John (1984) Agenda, Alternatives and Public Policies, Boston: Litlle Brown.

Krook, Mona Lena (2008) "La adopción e impacto de las leyes de cuotas de género: una perspectiva global” en Marcela Ríos Tobar (ed) Mujer y Política. El impacto de las cuotas de género en América Latina, Santiago de Chile: FLACSO, 27-59.

Lahera Parada, Eugenio (2002), Introducción a las Políticas Públicas, México: Fondo de Cultura Económica.

Lopreite, Débora (2015) “Gender Policies in Argentina after Neoliberalism: Opportunities and Obstacles for Women's Rights”, Latin American Perspectives 42 (1), 64-73. 
Marx, Jutta; Jutta Borner y Mariana Caminotti (2007) Las Legisladoras. Cupos de género y política en Argentina y Brasil, Buenos Aires: Siglo XXI.

Meny, Yves y Thoening, Jean-Claude (1992) Las políticas públicas, Barcelona: Ariel. Moreau de Justo, Alicia (1945) La mujer en la democracia, Buenos Aires: El Ateneo.

Ostrom, Elinor (2010) “Elección racional institucional. Evaluación del marco del análisis y desarrollo institucional” en Paul Sabatier (ed.) Teorías del proceso de las políticas públicas, Buenos Aires: Presidencia de la Nación, Jefatura de Gabinete de Ministros, 23-68.

Palermo, Silvana (1998) "El sufragio femenino en el Congreso Nacional: Ideologías de género y ciudadanía en la Argentina (1916-1955)”. Boletín del Instituto de Historia Argentina y Americana "Dr. Emilio Ravignani", Tercera Serie No 16 y 17, 151-178.

Palermo, Silvana (2007) "Quiera el hombre votar, quiera la mujer votar: género y ciudadanía política en Argentina (1912-1947)" Ponencia presentada en "El sufragio femenino en América Latina: Jornadas en conmemoración de los sesenta años de la ley 13010”, Universidad de Tres de Febrero, 29, 30 y 31 de Agosto de 2007.

Parsons, Wayne (1995) Public Policy. An Introduction to the Theory and Practice of Policy Analysis, Aldershot: Edward Elgar.

Pressman, Jeffrey y Aaron Wildavsky, (1984) Implementation, Berkeley: University of California Press.

Ríos Tobar, Marcela y Andrés Villar, (2006) Cuotas de género. Democracia y representación, Santiago: FLACSO.

Romero, Juan Carlos (1995) Breve historia contemporánea de la Argentina, Buenos Aires: Fondo de Cultura Económica.

Subirats, Joan (1992) Análisis de Políticas Públicas y Eficacia de la Administración, Madrid: Ministerio para las Administraciones Públicas.

Tamayo Sáez, Manuel (1997) “El análisis de las Políticas Públicas” en Rafael Bañón y Ernesto Carrillo (eds) La Nueva Administración Pública Madrid: Alianza, 281-312.

Torre, Juan Carlos (1989) “Interpretando (una vez más) los orígenes del peronismo”. Desarrollo Económico 31 (121), 525-548. 
Tula, María Inés (2002) "La Ley de Cupos en la Argentina: La participación de las mujeres en los órganos representativos de gobierno”, en Silvia Vázquez (comp) Hombres públicos, mujeres públicas, Buenos Aires: Fundación Friedrich Ebert y Fundación Karakachof, 59-89.

Valobra, Adriana María (2008) “La ciudadanía política de las mujeres y las elecciones de 1951" Anuario del Instituto de Historia Argentina $N^{\circ} 8$ de la Facultad de Humanidades y Ciencias de la Educación perteneciente a la Universidad Nacional de la Plata, 53-89.

Zahariadis, Nikolaos (2012) "El marco de las corrientes múltiples. Estructura, limitaciones, perspectivas" en Paul Sabatier (ed.) Teorías del proceso de las políticas públicas, Buenos Aires: Presidencia de la República,Jefatura de Gabinete de Ministros, 69-98.

\section{Fuentes oficiales:}

Ley 8871.

Ley 13010.

Ley 24012.

Decreto $2125 / 83$

Decreto $379 / 93$.

Decreto $1246 / 00$.

Decreto 451/05.

Diario de sesiones de la Honorable Cámara de Senadores de la Nación (años 1946 y 1990).

Diario de sesiones de la Honorable Cámara de Diputados de la Nación (años 1947 y 1991). 